\title{
La precaria independencia de la judicatura peruana. La amovilidad judicial desde los inicios de la república hasta el reformismo castillista, 1824-1860*
}

\author{
The Precarious Independence of Peruvian Judiciary. \\ Irremovability of Judges since the Early Republic \\ until the Castillista Reform, 1824-1860
}

\author{
Pablo Whipple Morán \\ ORCID iD: http://orcid.org/0000-0001-7405-0340 \\ Pontificia Universidad Católica de Chile
}

Este artículo analiza la dependencia de la judicatura peruana del poder político a través del estudio de las leyes y prácticas referidas a la amovilidad judicial durante los primeros años de la república hasta la reforma al sistema judicial llevada adelante durante el segundo gobierno de Ramón Castilla. El artículo argumenta que lejos de ser una reforma de carácter liberal, como otras impulsadas por la Constitución de 1856, el gobierno de Castilla buscó limitar la independencia de los jueces profundizando en el sometimiento de estos al ejecutivo.

Palabras Clave: Perú; Administración de Justicia; Formación del Estado; Jueces; Abogados.

This article analyses laws and practices that limited judicial independence in Peru since de beginning of the republican period until the judicial reform carried out by Ramon Castilla during his second government. The article argues that far from being a liberal reform as others promoted by the 1856 Constitution, Castilla's government tried to reinforce the historical dependency of judges to political power.

KeYwords: Peru; Administration of Justice; State Formation; Judges; Lawyers.

Copyright: (C) 2019 CSIC. Este es un artículo de acceso abierto distribuido bajo los términos de la licencia de uso y distribución Creative Commons Reconocimiento 4.0 Internacional (CC BY 4.0).

* Este artículo es producto de una investigación financiada por el Fondo de Ciencia y Tecnología de Chile (Fondecyt), Proyecto Regular 1150779, titulado «Expansión y formalización de la justicia republicana en Perú. Poder Judicial y formación del Estado, 1823-1872». 
Un remitido publicado en el periódico El Comercio de Lima a inicios de 1855 anunciaba que la revolución liderada por Ramón Castilla era distinta a las que el país había vivido en años anteriores. Según el autor, esta era una «revolución de principios», que incluso generaba más apoyo popular que la propia guerra por la independencia, dado que el pueblo estaba «cansado de tan largos disturbios y dilapidaciones», por lo que ahora quería «reformas que aseguren su bienestar y prosperidad».

Para el autor del artículo, de todas las reformas que el país necesitaba, ninguna era más urgente que la reforma a la administración de justicia. Según sus palabras, el sistema judicial se encontraba dominado por «los empeños, influjos y cohechos», situación que los mismos jueces reconocían al confesar que «frecuentemente no pueden resistir a la presión moral que se ejerce sobre ellos en muchos casos». En conclusión, el artículo destacaba que bajo el sistema imperante, «los ricos y poderosos» podían «eludir o torcer la ley a su favor», siendo necesario restaurar «el imperio de la ley» como «único norte que guie a los magistrados».2

Tal como describía el artículo, el sistema judicial republicano vivía bajo constante crítica desde su instauración en 1823. Artículos en la prensa que acusaban la corrupción de los jueces y funcionarios judiciales eran una constante, como también lo eran las críticas a otros agentes del sistema como abogados, litigantes y tinterillos, quienes eran acusados de intentar influir sobre las decisiones de los magistrados y de entorpecer los procesos judiciales. ${ }^{3}$ A esto se sumaba una crónica precariedad de las condiciones materiales y humanas bajo las cuales los jueces debían cumplir sus funciones, las que, según los magistrados, los hacía un blanco fácil para la corrupción y generaba inestabilidad sobre la administración de justicia. ${ }^{4}$

El movimiento liderado por Ramón Castilla se propuso realizar una profunda reforma del sistema judicial peruano por estas mismas razones. Si bien se podría pensar que el plan reformador de Castilla era solo una respuesta directa a las constantes acusaciones de corrupción que afectaron al gobierno anterior, ${ }^{5}$ su reforma era efectivamente parte de un plan mayor

1 El Comercio 4651, Lima, 1 de febrero de 1855, 4.

2 Idem.

3 Sobre las tácticas ilegales usadas para dilatar los procesos judiciales, ver Whipple, 2013a, capítulo 7. Sobre el actuar de agentes informales como los tinterillos, ver Aguirre, 2012.

4 Sobre las pobres condiciones materiales que debieron enfrentar los jueces peruanos, ver Whipple, 2013b.

5 Sobre la corrupción durante el gobierno de Echeñique, ver principalmente Quiroz, 1987; 2008, 116-129. 
de reformas de carácter liberal que afectarían distintos ámbitos de la vida nacional y darían al país una estabilidad institucional que hasta ese momento le había sido elusiva. ${ }^{6}$

Dentro de ese proyecto mayor, el gobierno reconocía la centralidad de la reforma judicial al definirla como «el principio de una nueva era de garantías públicas y privadas», razón por la cual anunciaba que sería «infatigable en observar la conducta de los magistrados a quienes ha considerado órganos de tan delicadas funciones». ${ }^{7}$ Fue así como, junto a una serie de medidas que buscaban agilizar los procedimientos judiciales, el gobierno de Castilla anunció otras que implicaban sendos cambios en el sistema judicial y que generaron intenso debate en el país. Una de ellas era la Ley de Amovilidad Judicial que permitiría al gobierno, según la Constitución de 1856 , remover a voluntad a los jueces de primera instancia y de cortes superiores y definir la duración de sus empleos. ${ }^{8}$

Con esta ley, el gobierno asumía un tema sensible que, según los detractores del proyecto, atacaba directamente la debida independencia del sistema judicial y además traería como consecuencia un importante desincentivo entre los buenos abogados que quisieran seguir la carrera judicial. ${ }^{9} \mathrm{El}$ debate sobre la independencia de la judicatura, sin embargo, no era una novedad y la propuesta del gobierno de Castilla de poder remover a su voluntad a los jueces y limitar su tiempo en los cargos no hacía más que reavivar una discusión que se venía dando con distintas intensidades desde 1823. Esa era la opinión de Manuel Atanasio Fuentes, para quien la ley de Castilla no hacía «nada nuevo», ya que, aunque constituciones anteriores aseguraban la inamovilidad de la judicatura, los empleados judiciales habían «sido siempre removidos y remeneados ad libitum», concluyendo que la Convención Nacional no hacía más que dar carácter constitucional a una práctica antigua. ${ }^{10}$

El estudio de los debates sobre la amovilidad judicial durante los primeros años de la república permite abordar el tema de la independencia de la judicatura republicana en su momento fundacional. A pesar de la impor-

6 Para una visión general del proyecto reformador de Castilla, ver Basadre, III, cap. XLVII. Sobre el liberalismo y la Constitución de 1856, ver Sobrevilla, 2004; Del Águila, 2013, 149-171. Sobre la riqueza del guano y la hacienda pública durante Castilla, ver Gootemberg, 1993.

7 Circular del Gobierno al presidente de la Corte Suprema y a los prefectos de los departamentos, Lima, 10 de abril de 1855, en Oviedo, 1863, XI, 401.

8 Junto a la Ley de Amovilidad, el gobierno propuso la «defensa libre» que buscaba permitir a los ciudadanos representarse ante los tribunales sin la obligación de hacerlo a través de un abogado, facilitando así el acceso a la justicia. Sobre los proyectos de defensa libre, ver Whipple, 2016.

9 El Comercio 4847, 27 de septiembre de 1855, 6.

10 Fuentes, 1866, II, 29-30. 
tancia del tema, este ha sido estudiado para el caso peruano principalmente en su dimensión actual, resaltando la incidencia que factores políticos e institucionales han tenido a la hora de limitar la independencia de la judicatura en los últimos cincuenta años, especialmente durante regímenes autoritarios. ${ }^{11}$ El estudio de la independencia de los jueces a inicios del siglo XIX, sin embargo, puede entregar luces sobre un problema que parece no ser exclusivo de la historia reciente del Perú y que se conecta con aspectos claves del proceso de formación estatal, como es la construcción de legitimidad de uno de los poderes del Estado en su intento por distanciarse de la supuesta corrupción y arbitrariedad que había caracterizado al antiguo régimen.

Desde esta perspectiva, el presente artículo tiene por objetivo contribuir a dos ámbitos de estudio que se relacionan entre sí. Por una parte, al estudio de la dimensión política de la administración de justicia y al problema de la gobernabilidad visto desde el desafío que implicó tanto la separación de poderes como los conflictos entre soberanías locales y nacionales en un contexto caudillista como el peruano durante la temprana república. ${ }^{12}$

El segundo ámbito se relaciona con el estudio de la formación del Estado y sus capacidades en materia judicial. Con respecto a esta última dimensión, buscamos aportar a lo que autores como Hillel David Soifer han descrito como la necesidad de distinguir las raíces históricas de las limitaciones de la capacidad estatal, para así tener un cabal entendimiento de sus manifestaciones actuales. ${ }^{13}$ Concordante con lo propuesto por Christopher Krupa y David Nugent, en esta investigación intentamos estudiar la capacidad estatal concentrándonos en las prácticas a través de las cuales lazos de identificación y consenso son solicitados o concedidos a los agentes del Estado. Siguiendo a Pierre Bourdieu, estos autores plantean que más que las grandes manifestaciones del poder estatal, la legitimidad del Estado se construye a través de las prácticas rutinarias de sus funcionarios. ${ }^{14}$

11 Para el análisis de la independencia de la judicatura en el Perú de las últimas décadas, ver entre otros, Pásara, 2010. Landa, 2001. Dargent, 2009. Para el siglo XIX existen algunos estudios que abordan la cultura legal y las ideas en torno a la labor de los jueces. Ver por ejemplo, De la Puente Brunke, 2011-2012. Ramos, 2007.

12 Sobre los conflictos entre soberanías locales y nacionales, ver entre otros Annino, 2003. Sobre la manifestación de esta tensión entre lo local y lo nacional en lo referido a la institucionalidad judicial en la república temprana, ver Galante, 2011. En lo relativo a la dimensión política de la administración de justicia existe amplia literatura para el caso Argentino. Sobre esta dimensión y específicamente sobre la separación de poderes y la independencia de la judicatura durante el siglo XIX, ver entre otros Candioti, 2010; Barriera, 2017; Corva, 2009.

13 Soifer, 2015, 2-3.

14 Krupa y Nugent, 2015, 11-12. 
Finalmente, para el caso específico del Perú decimonónico, el estudio de la reforma judicial promovida luego de la revolución contra Echeñique nos permite contribuir al debate sobre el posible carácter liberal de las reformas llevadas adelante por Castilla y el impacto que estas pudieron tener en el proceso de centralización del poder estatal. Al respecto, este artículo propone que el proyecto de amovilidad judicial, más que una reforma de carácter liberal, buscó limitar la independencia de la judicatura intentando profundizar en el sometimiento del poder judicial al poder político que había sido la norma desde la creación de la justicia republicana.

\section{La histórica dependencia de la judicatura al poder político.}

En julio de 1840, el encargado de negocios de Estados Unidos en Perú, James Pickett, informaba a su país que en ninguna parte del mundo se podía tener «menos confianza en la integridad de los magistrados» que en Perú, principalmente por «las interminables y desmoralizadoras guerras civiles, el derroche oficial de los tiempos, la pobreza de algunos jueces, su dependencia del ejecutivo [...] y por último, sus salarios que son pagados por muy poca regularidad». ${ }^{15}$

La opinión de Pickett no era exagerada y en parte era compartida no solo por muchos peruanos sino incluso por los mismos magistrados del país. Para los jueces, su independencia se veía permanentemente amenazada ante las precarias condiciones materiales en las que debían realizar su trabajo, ${ }^{16}$ a lo que se sumaba una constante sumisión al poder ejecutivo que los transformaba en funcionarios de segunda categoría siempre dependientes de la voluntad de prefectos e intendentes. ${ }^{17}$

A pesar de lo anterior, las constituciones de 1823 y 1826 garantizaban la independencia de la judicatura al establecer que los jueces eran inamovibles y que permanecerían en sus cargos mientras sus servicios no fueran contra la ley. Solo podrían ser suspendidos de sus cargos ante faltas graves como el soborno y la prevaricación. ${ }^{18}$ De manera más explícita aún, el

15 Comentarios de J. C. Pickett sobre el discurso de Gamarra al Congreso. Pickett a Forsyth, Lima, 15 de julio de 1840. United States National Archive, Despatches 1826-1906, roll 5, citado por Quiroz, 2008, 117.

16 Whipple, 2013b, 61-67, 71-76.

17 Sobre la temprana dependencia del poder judicial y la conflictividad entre jueces y representantes del ejecutivo, ver Bilot y Whipple, 2014; Whipple, 2015.

18 Constitución Política de la República Peruana, 1823, artículos 97 y 109; Constitución Política para la República Peruana, 1826, artículos 98 y 99. En Oviedo, 1861, I, 39-41, 67. 
artículo 103 de la Constitución de 1828 establecía que el poder judicial era independiente, a lo que se agregaba en el artículo 104 que los jueces eran perpetuos, no pudiendo ser destituidos «sino por juicio y sentencia legal». ${ }^{19}$

La garantía de inamovilidad establecida por distintas constituciones, sin embargo, no era respetada por las cambiantes autoridades políticas, quienes al asumir el poder ejecutivo o legislativo de la nación muchas veces desconocían la legitimidad de los jueces nombrados bajo la vigencia de constituciones previas. Así lo hacía ver un artículo publicado en El Mercurio Peruano pocos días después de promulgada la Constitución de 1828, argumentando que si bien cada constitución establecía la inamovilidad de los jueces, esta garantía era eludida, con el escándalo de «plantificar la nueva constitución con abierta infracción de los mismos principios que ella dice garantizar». ${ }^{20}$

Uno de los casos más sonados en este sentido ocurrió en 1831, cuando a través de leyes especiales el Senado (cuyo presidente, Andrés Reyes, era por entonces también jefe provisorio del ejecutivo) decretó la necesidad de ejecutar legislación que se encontraba pendiente desde 1828, en particular cumplir con los artículos 105 y 113 de la Constitución respecto a la elección de vocales de la Corte Suprema y de las cortes superiores del país. Fue así como el gobierno exoneró a los jueces en ejercicio de dichas cortes para nombrar nuevos vocales, varios de los cuales eran miembros del mismo Senado. ${ }^{21}$

Para los jueces de la Corte Suprema despojados de sus cargos, el actuar de Andrés Reyes era una «monstruosidad», haciendo ver que «si aquel que da las leyes las ejecuta también, ya no habrá más regla que su voluntad despótica». ${ }^{22}$ Para Fernando López Aldana, uno de los jueces exonerados, en todas partes del mundo «los buenos jueces han sido siempre respetados e inamovibles en sus plazas», por lo que calificaba los medios de los que se había valido el gobierno para removerlo de su cargo de «tiránicos y arbitrarios». ${ }^{23}$ De la misma forma, Benito Laso, otro de los jueces exonerados,

19 Constitución Política de la República Peruana, 1828, arts. 103 y 104. En Oviedo, 1861, I, 89.

20 El Mercurio Peruano 228, 12 de mayo de 1828, 3.

21 Ley del 1 de agosto de 1831 disponiendo que el Ejecutivo proceda a dar cumplimiento a todas las leyes publicadas para la marcha del régimen constitucional; Ley del 20 de agosto de 1831 declarando establecida la Corte Suprema de Justicia; Ley del 20 de agosto de 1831 declarando constitucionalmente establecidas las cortes de Lima, Cuzco, Arequipa y La Libertad. En Quirós, 1837, $56,61-62$.

22 Colección de los recursos de los antiguos magistrados, 1832, 12.

23 Ibidem, 7. 
opinaba que el actuar del gobierno era un «atentado cometido contra los patriotas más beneméritos, contra magistrados rectos, contra ciudadanos honrados, y más que esto, contra la independencia misma del poder judicial e inamovilidad de los magistrados que lo ejercen». ${ }^{24}$

La precaria independencia de la judicatura era afectada efectivamente por la inestabilidad política que vivía el país. A pesar de la inamovilidad decretada por las distintas constituciones, algunos gobiernos creían necesario remover a los jueces nombrados por gobiernos anteriores considerados ilegítimos. Esta práctica, aunque no estaba sancionada legalmente, se transformó en costumbre y no solo afectó a los jueces de las altas cortes, sino también a los jueces de primera instancia y otros funcionarios del poder judicial. Fue así como el presidente Agustín Gamarra dictó una serie de decretos una vez derrotada la Confederación Perú Boliviana para restituir en sus cargos a fiscales, relatores, jueces de primera instancia e incluso a escribanos que hubiesen sido nombrados o hubiesen apoyado al «gobierno intruso» liderado por Andrés de Santa Cruz. ${ }^{25}$

Pocos meses después, la Constitución de 1839 promulgada durante el mismo gobierno de Gamarra, estableció como atribución del presidente de la República el «suspender por cuatro meses a lo más, y trasladar a cualquier funcionario del Poder Judicial, cuando a su juicio lo exija la conveniencia pública». ${ }^{26}$ Aunque se respetaba la perpetuidad de los cargos, el ejecutivo tenía desde ahora la autoridad legal para redestinar a los jueces a su voluntad, sin consultar los traslados con las cortes superiores o la Corte Suprema. En otras palabras, lo que antes podía ser considerada una práctica legítima desde un punto de vista político pero inconstitucional, pasaba ahora a estar sancionada por la ley.

La traslación de jueces se hizo una práctica común en la década de 1840, aunque muchas veces estas medidas eran resistidas por los jueces e incluso por las comunidades afectadas. Para Santiago Negrón, juez de Huánuco que fue notificado de su traslado a Cañete en 1846, más que una herramienta que buscara perfeccionar la administración de justicia, la traslación era sencillamente una herramienta política que en su caso personal se había desatado por disputas con el prefecto local. Efectivamente, el prefecto

24 Ibidem, 9.

25 Documentos no numerados fechados entre el 22 de febrero y el 13 de marzo de 1839 Archivo General de la Nación (AGN), Ministerio de Justicia, Ramos del Ministerio de Justicia, Prefectura de Arequipa, RJ 1.1.1.

26 Constitución Política de la República Peruana dada por el Congreso General el diez de noviembre de 1839. En Oviedo, 1861, I, 132. 
de Junín, Mariano Eduardo Rivero, había enviado al Ministerio de Justicia una consulta reservada en la que informaba que en el juez existía «cierta tendencia para desunir a las familias de Huánuco», información que en definitiva había sido suficiente para decidir el traslado. ${ }^{27}$

Además de presentar testimonios sobre su comportamiento «conciliatorio y amigable» en Huánuco, el juez Negrón opinaba que no existía razón para que el gobierno decidiera la traslación de un juez ya que el propio sistema judicial tenía los mecanismos para castigar a los jueces que no cumplieran sus funciones. Su «traslación inmerecida» era un «desaire» que afectaba su autoridad como juez, pero además era manifestación de los «riesgos a que está expuesta la administración de justicia por la persecución que padecen los jueces íntegros», situación que no cambiaría de no reconocerse a la judicatura como una carrera permanente e «incompatible con las traslaciones». ${ }^{28}$ Para Negrón, «una de las principales garantías de la administración de justicia y del orden público» era «la inamovilidad de los jueces», pero si se dejaba a los prefectos influir sobre el poder judicial, como lo hacían «de costumbre», este poder del Estado estaría «sometido a sus caprichos, y desaparecerá su independencia sancionada por la constitución». De esta forma, el país sufriría «males de la mayor consideración, pues no los puede haber mayores que el dejar una grande influencia al poder [ejecutivo] sobre los juicios, pues si este puede disponer de la suerte de los jueces, ya puede disponer de la suerte de todos los ciudadanos», haciendo además que los jueces vivan «en la incertidumbre de su suerte, y en continuo peligro», si han «tenido la desgracia de disgustar a un prefecto». ${ }^{29}$

Un artículo publicado en El Comercio de Lima en septiembre de 1846 planteaba una posición semejante a la del juez Negrón frente a la facultad del ejecutivo de trasladar a los jueces. Para el autor, el artículo 87 de la constitución no era en sí mismo un problema ya que la traslación de jueces no iba en contra de los derechos de los ciudadanos ni era opresiva al poder judicial, siempre y cuando las traslaciones se hicieran efectivamente cuando «lo exigiera la conveniencia pública». La traslación debía ser un instrumento que ayudara a reforzar la «estimación pública» del juez y «asegurar

27 Conflicto entre el Juez de Huánuco, Casimiro Negrón, y el Prefecto de Junín, Huánuco, 15 de julio de 1846. AGN, Ministerio de Justicia, Juzgados, Primera Instancia, 10.1.235, documento no numerado, $2 \mathrm{v}$.

28 Conflicto entre el Juez de Huánuco, Casimiro Negrón, y el Prefecto de Junín, Huánuco, 20 de septiembre de 1846. AGN, Ministerio de Justicia, Juzgados, Primera Instancia, 10.1.235, documento no numerado, $2 \mathrm{v}$.

29 Ibidem, 3. 
su duración en el destino», ya que «solo estas condiciones le darán la fuerza necesaria para administrar justicia entre el poderoso y el desvalido». A diferencia de los prefectos y subprefectos, continuaba el artículo, los jueces no contaban «con soldados y gendarmes para hacerse obedecer» y de ahí la importancia de que el ejecutivo reforzara el prestigio de la judicatura. ${ }^{30}$

A juicio del articulista, sin embargo, esta no era la realidad. Inexplicablemente el ejecutivo trasladaba a los magistrados acusados de corruptos y venales en vez de juzgarlos y destituirlos en caso de comprobarse el delito, lo que terminaba afectando también a los buenos jueces que debían dejar sus destinos para trasladarse ahí donde había existido un mal juez. Frente a esta situación, los litigantes abusaban levantando muchas veces falsas acusaciones contra un juez para así forzar su traslado, al mismo tiempo que se ponía en permanente entredicho el prestigio y la legitimidad de la magistratura. En consecuencia, para los malos jueces la traslación, más que un castigo por sus excesos, era la posibilidad de repetirlos en su nuevo destino, mientras que para el buen juez, era una «pena grande, humillante [y] aflictiva», que «anula la independencia del poder judicial». ${ }^{31}$

Finalmente, el articulista llamaba la atención sobre los prefectos, a quienes veía como a los máximos instigadores contra la legitimidad y estabilidad de la judicatura. Luego de veinte años de revolución, los prefectos eran «más temibles que el mismo gobierno en sus departamentos», y el Perú se había transformado en un lugar donde un juez no podía ser independiente ni proteger su honor e intereses ya que «la arbitrariedad [y] antipatía del Presidente, del Ministro y aun las de un Prefecto bastan para desterrarlo o destituirlo con una traslación constitucional en la forma en que se usa hoy».32

Para el juez Tomás Dávila, la notificación de su traslado en 1848 desde Moquegua a la judicatura de Condesuyos era efectivamente un castigo. Luego de haber servido por cinco años como relator de la Corte Superior de Lima y por diez años como juez de primera instancia de Moquegua, el traslado a «una lejana Provincia», donde no existía «la necesaria y frecuente comunicación con Moquegua», podía ser entendido como una degradación en su carrera judicial. Por eso mismo, junto con resignarse «al sacrificio de pasar a Condesuyos», pedía que el traslado no se entendiera como una

30 El Comercio 2178, 22 de septiembre de 1846, 3.

31 Idem.

32 El Comercio 2179, 23 de septiembre de 1846, 3. Sobre el poder de los prefectos y de las autoridades locales representativas del poder ejecutivo, ver Ragas, 2005, 225-227. 
penalización, ya que en su conciencia no encontraba «haber delinquido en lo menor contra el Supremo Gobierno, y mucho menos en el ejercicio de las delicadas funciones de juez de Moquegua».33

Efectivamente, parecían no existir razones que justificaran el traslado de Tomás Dávila asociadas a alguna acusación en su contra por un mal desempeño en la judicatura. Es más, cuatro años antes los mismos vecinos de Moquegua habían intercedido ante las autoridades para evitar que el juez fuera trasladado, esta vez a Tarapacá, destacando la «intachable [...] conducta pública y privada» del juez. En una carta dirigida al prefecto del departamento, 66 vecinos de Moquegua pedían que la autoridad local hiciera llegar al gobierno central la petición para que no se trasladara al juez Dávila debido a sus «talentos, actividad y honradez». ${ }^{34}$

En una nueva carta dirigida a las autoridades, los vecinos de Moquegua insistían en su petición resaltando los «principios incontrastables de legitimidad» que habían llevado al juez Dávila a oponerse al régimen de Vivanco y apoyar el orden constitucional vigente. Sumado a lo anterior, llamaban a las autoridades a fortalecer la estabilidad y respetabilidad de los funcionarios judiciales, la que se lograría respetando su inamovilidad, a menos que existiera «un delito probado o sentencia que los condene». La firmeza del Estado en el respeto de estos principios evitaría el «fomento de la empleomanía que aqueja a la República», vicio que, según los habitantes de Moquegua, era una «causa de trastornos y revueltas frecuentes», ya que «con el descontento de los removidos sin causa se acumularía un combustible pronto a incendiarse». .35

Con todos estos antecedentes, el prefecto escribió al secretario general de la Junta de Gobierno Provisorio de la República, haciendo ver la «voluntad de toda una población muy sensata y juiciosa» que había resentido de manera unánime, como pocas veces se había visto antes en el Perú, el traslado de un juez, por lo que recomendaba la revocación de la medida ${ }^{36}$ decretándose finalmente en marzo de 1845 que el juez Dávila

33 Petición del juez de Moquegua, Arequipa, 25 de agosto de 1848. AGN, Ministerio de Justicia, Corte Superior de Arequipa, RJ 5.2.91, documento no numerado, 1v.

34 Petición de los vecinos de Moquegua, Moquegua, 5 de noviembre de 1844. AGN, Ministerio de Justicia, Ramos del Ministerio de Justicia, Prefectura de Moquegua, RJ 1.4.11, documento no numerado, 1-2.

35 Segunda petición de los vecinos de Moquegua, sin fecha. AGN, Ministerio de Justicia, Ramos del Ministerio de Justicia, Prefectura de Moquegua, RJ 1.4.11, documento no numerado, 1v-2.

36 Oficio del prefecto de Moquegua, Tacna 1 de diciembre de 1844. AGN, Ministerio de Justicia, Ramos del Ministerio de Justicia, Prefectura de Moquegua, RJ 1.4.11, documento no numerado, $1-1 \mathrm{v}$. 
volviera a «servir la judicatura de Moquegua por así exigirlo la conveniencia pública». ${ }^{37}$

El juez no corrió la misma suerte en 1848. Resignado frente a una nueva decisión del gobierno central de trasladarlo a Condesuyos, esperaba que su nueva destinación fuera solo temporal dada la inestabilidad política que se vivía por ese entonces en Moquegua. Debido a eso, elevó una solicitud al gobierno central en la que pedía no perder la propiedad constitucional de su destino en Moquegua, pensando en su posterior retorno. Además de esto, solicitaba tres meses de licencia para encargarse de sus asuntos personales en Moquegua antes de trasladarse y un adelanto de 600 pesos para poder costear su viaje y el de su familia a Chuquibamba, capital de Condesuyos en el departamento de Arequipa, distante más de cien leguas por intrincados caminos, de cuyo monto gastaría más de la mitad solo «en el flete de bestias para su esposa e hijos, respectiva servidumbre y el más necesario equipaje». ${ }^{38}$

La principal preocupación del juez, sin embargo, era no perder futuros beneficios a los que podría acceder como funcionario público. Por eso aceptaba un traslado que le parecía degradante, ya que de renunciar a su nuevo destino temía que el gobierno lo juzgara como «un indócil e inobediente funcionario» y perder «quince años de buenos y leales servicios» a la nación, manifestación de sus «nobles y generosas aspiraciones para el buen servicio de la república». ${ }^{39}$

A pesar de su intachable historial como juez en Moquegua, la solicitud de Dávila no fue acogida por el gobierno, declarando no ha lugar tanto a su solicitud de traslado temporal como a la de mantener la propiedad de la judicatura de Moquegua. Tampoco se aceptó la solicitud de gastos de traslado por no estar considerados en el presupuesto público, obligándolo a financiar con su propio patrimonio su traslado a su nuevo destino, cosa que debía hacer en solo 30 días, negándosele la petición de tres meses de licencia para el arreglo de sus negocios. ${ }^{40}$

Aunque las tempranas constituciones peruanas garantizaban la independencia del poder judicial y la inamovilidad de los jueces, en la práctica esta se veía amenazada por la inestabilidad política que afectó al país en

37 Restitución del juez Tomás Dávila, Lima 6 de marzo de 1845. AGN, Ministerio de Justicia, Ramos del Ministerio de Justicia, Prefectura de Moquegua, RJ 1.4.11, documento no numerado, 1-1v.

38 Petición del juez de Moquegua, Arequipa, 25 de agosto de 1848. AGN, Ministerio de Justicia, Corte Superior de Arequipa, RJ 5.2.91, documento no numerado, 2.

39 Ibidem, $1 \mathrm{v}$.

40 Ibidem, $2 \mathrm{v}$. 
las décadas posteriores a su independencia. Esta falta de independencia se legitimaba inicialmente por las disputas políticas y las prácticas asociadas a las disputas del poder, pero a partir de 1839 la capacidad del ejecutivo de trasladar a los jueces sin consulta a las cortes superiores adquirió rango constitucional. Como dejan de manifiesto los casos de los jueces Negrón y Dávila, esta dependencia obligaba a la politización de la judicatura y a encontrar estabilidad dependiendo de sus relaciones con los representantes del poder ejecutivo, ya fuese a nivel local, frente al prefecto de turno, o a nivel nacional. Lo paradójico, sin embargo — como veremos más adelante-, es que en la medida en que el país fue ganando mayor estabilidad política hacia la década de 1850, se intentó poner aún mayores límites a la independencia del poder judicial a través de leyes que permitían al ejecutivo no ya trasladar a los jueces sino además removerlos y definir la duración de sus empleos.

\section{El traslado como herramienta contra la corrupción de la judicatura}

Al cumplirse un nuevo aniversario de la independencia del país, el ministro de Justicia, Felipe Pardo, presentó la memoria de su cartera ante el Congreso el 28 de julio de 1849. El diagnóstico del ministro no era alentador, anunciando que debía comenzar sus palabras con la «dolorosa pero necesaria confesión» de que los progresos en materia judicial no se correspondían con el «adelantamiento que indudablemente se nota en la civilización peruana». ${ }^{41}$ Había infinidad de aspectos que mejorar, entre ellos la legislación, que resultaba confusa e inapropiada para los tiempos que se vivían, pero según el ministro también se debía dotar al presidente de la República de atribuciones que permitieran mejorar la administración de justicia, entre ellas, facilitar la traslación de jueces.

Según las palabras del ministro, el primer gobierno de Ramón Castilla había «cumplido escrupulosamente con respetar la independencia judicial», limitándose a las atribuciones que le otorgaba la constitución, entre ellas el poder trasladar jueces. Sin embargo, el gobierno reconocía la existencia de dos trabas en el ejercicio de dicha atribución constitucional. Por una parte, los jueces trasladados, amparados por legislación de 1796 y 1832, argumentaban que el funcionario trasladado contra su voluntad tenía el derecho de conservar el sueldo de su anterior destino en caso de ser trasladado a uno

41 El Comercio 3041, 23 de agosto de 1849, 2. 
de menor jerarquía, generando un gravamen extraordinario al Estado. El gobierno se había negado ante estas solicitudes sosteniendo que los sueldos de los jueces dependían de la «abundancia o carestía de recursos de las provincias y al menor o mayor número de causas que puedan ocurrir en ellas». La segunda limitante había sido establecida por una ley de 1845, que exigía que las traslaciones debían ser entre cargos equivalentes. Según el gobierno, esto no podía garantizarse y ponía obstáculos para que se llenaran «por medio de traslaciones, las vacantes que ocurran», por lo que el ministro pedía al Congreso «una ley que le autorizase al efecto», lo que «simplificaría considerablemente el ejercicio de la atribución relativa a traslaciones». ${ }^{42}$

Esta última petición del gobierno podía ser vista como un claro ataque a la independencia de la judicatura. Los traslados no eran una forma de nominar jueces y llenar vacantes — procedimientos que estaban claramente establecidos por la constitución y de los que participaban las cortes superiores enviando ternas al gobierno- , sino que debían limitarse a «la conveniencia pública», según establecía la constitución. Un artículo publicado en El Comercio pocas semanas después de la intervención del ministro ante el Congreso, llamaba a los parlamentarios a no afianzar aún más la «facultad terrible» del ejecutivo, y criticaba la intolerable «indiferencia con que el Poder Legislativo ha mirado hasta ahora la monstruosa, contradictoria y funesta atribución que concede la Carta al Presidente de la República para trasladar a su arbitrio a los funcionarios del Poder Judicial». A diferencia del ministro, para el autor del artículo esta facultad era una amenaza efectiva contra la independencia de la judicatura y podía «ser de funestísimas consecuencias a los jueces y a la sociedad». ${ }^{43}$

Así como la independencia de la judicatura había sido afectada por la inestabilidad política vivida por el Perú hasta entonces, su independencia se veía ahora también amenazada por el embrionario esfuerzo de Castilla por centralizar el poder y fortalecer al ejecutivo. Como argumenta Carmen McEvoy, el Estado castillista proponía una ideología «autoritario-cohesionadora», que promovía un proyecto que buscaba «la reconstrucción de la legitimidad política perdida, el respeto por la autoridad, y la vuelta a la unidad nacional»; al mismo tiempo que caracterizaba a los disidentes como «promotores del caos y el divisionismo» que «ponían en peligro el bien común de todos los peruanos». ${ }^{44}$

42 Idem.

43 El Comercio 3056, 11 de septiembre de 1849, 4.

44 McEvoy, 1997, 26-30. 
En este contexto, el argumento predominante para la traslación de un juez no solo sería su potencial condición de adversario político sino también la potencial amenaza del juez al bien común de los peruanos. Según un artículo publicado en 1852, durante la presidencia del general Echeñique, la facultad de trasladar jueces era el «único freno que puede contener los abusos del Poder Judicial». Los jueces no eran ángeles, según el autor, sino «hombres capaces de pecar gravemente» y la traslación de un mal funcionario era una «atribución necesaria y utilísima a la comunidad», pues al trasladarlo se libraba «a un pueblo de los males que le causa». ${ }^{45}$

Al mal actuar de un juez se unían otras amenazas que podían ser solucionadas con la traslación, según el artículo. Los jueces destinados por mucho tiempo en un mismo lugar sentenciaban de un «modo parcial e injusto» debido a que adquirían «relaciones muy íntimas, amistades estrechas, compadrazgos y contratos con los vecinos». La inamovilidad de los jueces iba además en contra de la igualdad ante la ley, debido a que los demás empleados civiles y militares podían ser trasladados a discreción del ejecutivo. «En una república como la nuestra no se reconocen jerarquías ni privilegios» y por eso mismo, según el artículo, las traslaciones podían afectar tanto a un juez de primera instancia como a un vocal de la Corte Suprema, quien no debía tener inconveniente de pasar a una corte superior. ${ }^{46}$

Hacia mediados del siglo XIX la inamovilidad de los miembros del poder judicial, sentenciada constitucionalmente, no solo se veía amenazada por las vicisitudes políticas sino que también era cuestionada como posible fuente de corrupción. Al no existir un cuerpo legal que reglamentara efectivamente la carrera funcionaria de los jueces de la república, estos quedaban a merced de la voluntad política de las autoridades de turno y la traslación de los jueces fue utilizada por distintos gobiernos sin distinción, incluyendo el de Echeñique. $\mathrm{Al}$ discutirse un nuevo proyecto constitucional luego del triunfo de Castilla, sin embargo, en vez de cuestionar esta práctica se buscó fortalecerla, profundizando aún más la dependencia de la judicatura al poder político.

\section{Segundo gobierno de Castilla y la Constitución de 1856}

Pocos días después del triunfo de Castilla sobre Echeñique, el prefecto de La Libertad informó al gobierno provisorio que, «en uso de las facultades

45 El Comercio 3999, 17 de noviembre de 1852, 3.

46 Idem. 
concedidas», había «removido de sus empleos en el ramo de justicia» a los doctores Rebaza y Castro, vocales de la Corte Superior del departamento, y a los jueces de primera instancia de Huamachuco y Lambayeque, Pedro Torres y Joaquín Borgoño. ${ }^{47}$ En el oficio enviado al gobierno, el prefecto explicaba que para justificar las remociones había tenido en cuenta el «juicio público» en contra de los magistrados, además de tener la convicción de que habían participado eficazmente «en el sostén de la ominosa tiranía de Echeñique», además de ser ineptos y corruptos, usurpando dichos puestos al «talento y a la honradez que simbolizan el programa» de la revolución triunfante..$^{48}$

La politización de los jueces era una realidad y no extraña que muchos de ellos hubiesen tomado partido durante la revolución, como tampoco extraña que aquellos que hubiesen apoyado a Echeñique sufrieran la represión del bando triunfante. ${ }^{49}$ Independientemente de esto, la remoción de jueces por orden de una autoridad local no dejaba de ser un acto que contravenía la constitución y, al igual que en el pasado, los prefectos serían piezas clave en el intento del gobierno de Castilla por reformar el sistema judicial.

La voluntad de reforma recibió inmediato apoyo en las páginas de periódicos como El Comercio, donde artículos remitidos por los lectores hacían ver al gobierno los distintos aspectos que era urgente cambiar. Un artículo publicado solo 10 días después del triunfo de Castilla apuntaba a la condición de vitalicios de los jueces y la poca fiscalización que existía sobre su labor. Por una parte, el autor argumentaba que si los miembros de los poderes ejecutivo y legislativo no eran vitalicios, no había razón para que lo fueran los miembros del poder judicial. En segundo lugar, hacía ver lo absurdo que resultaban ser los traslados de jueces, argumentando que si existían acusaciones contra un juez y se comprobaba el delito, el juez delincuente no dejaría de serlo en su nuevo destino. ${ }^{50}$

Un nuevo artículo publicado el 5 de febrero de 1855 pedía al recientemente nombrado ministro de Justicia, Pedro Gálvez, que pusiera fin a los «desmanes» de la judicatura, exigiendo «una reforma radical en todo aquello que es concerniente al ramo de la administración de justicia». El

47 Oficio sobre jueces exonerados, Trujillo 30 de enero de 1855. AGN, Ministerio de Justicia, Ramos del Ministerio de Justicia, Prefectura de La Libertad, RJ 1.3.10, documento no numerado, 1.

48 Idem.

49 Esta práctica no solo afectaba a los jueces. Víctor Peralta ha descrito el «reparto de beneficios» luego del triunfo de Castilla, lo que implicó repartición de cargos en el gobierno central, que por cierto se replicó a nivel local. Peralta, 2013, 214-217.

50 El Comercio 4636, 15 de enero de 1855, 4. 
artículo culpaba principalmente a los jueces de los problemas que enfrentaba el sistema, argumentando que si las causas se eternizaban se debía a «la impericia o descuido de los señores vocales», a quienes se debía imponer plazos perentorios en el despacho de las causas. ${ }^{51}$

Frente a la «polvareda de indigestos artículos» que exigían reformas, un nuevo remitido publicado por «un verdadero amigo del libertador» advertía que implementar los cambios no sería una tarea fácil. Por eso recomendaba al gobierno tener «tino, sagacidad y prudencia», ya que para llevar adelante las reformas tendría que dar «muchas batallas semejantes» a la de La Palma, pues era necesario para ello «chocar con los intereses privados de muchísimas personas que son siempre más persuasivos y ruidosos». Además, una reforma tan profunda como la que proponía el gobierno, abriría «la puerta a la chismografía de los aspirantes; al soplo maléfico de los perversos; a la novelería de los imbéciles; a los anónimos y denuncias tenebrosas y secretas de la malevolencia, y a todas las maquinaciones de la envidia». ${ }^{52}$

El autor del artículo concordaba con la necesidad de hacer reformas, pero había que consensuarlas consultando «previamente la voluntad de los pueblos y recoger, por así decirlo, la pluralidad absoluta de votos de la opinión pública», tal como había hecho el presidente Castilla en su gobierno anterior, lo que le había permitido instaurar «un dilatado periodo de paz, orden y progreso». Por eso recomendaba al presidente distanciarse del «grito discordante del aspirantismo» y del «vértigo innovador». De lo contrario, «sería mucho mejor dejar las cosas como estaban», en vez de «mover desde sus cimientos todo el edificio social». ${ }^{53}$

Luego de derrotar definitivamente al régimen de Echeñique en la batalla de La Palma, el plan de gobierno de Ramón Castilla no era precisamente uno guiado por la cautela. El 31 de marzo de 1855 se procedió por decreto a nombrar a todos los empleados judiciales del territorio, incluyendo los vocales de la Corte Suprema de Justicia y de las cortes superiores de Lima, La Libertad, Ayacucho, Cuzco, Arequipa y Puno, además de 59 jueces de primera instancia para todo el territorio nacional. ${ }^{54}$ Siguiendo informes como el del prefecto de La Libertad, citado en páginas anteriores, a través de este

51 Idem.

52 El Comercio 4686, 14 de marzo de 1855, 4.

53 Idem.

54 Decreto nombrando el personal de todos los tribunales y juzgados de la República, Chorrillos, 31 de marzo de 1855. En Oviedo, 1864, XII, 59-60. 
decreto el gobierno procedió a reemplazar a todos los vocales y jueces de primera instancia exonerados y a confirmar en sus puestos a aquellos que no eran reconocidos como enemigos de la revolución triunfante.

En departamentos como Puno, que a diferencia de La Libertad había tempranamente tomado partido por el bando de Castilla ya en abril de $1854,{ }^{55}$ el prefecto cumplió con enviar un informe detallado del estado de la administración de justicia en su territorio a inicios de 1855, sin reportar exoneraciones. Según el prefecto, dos de los cuatro vocales de la Corte Superior de Puno eran jueces de dilatada experiencia en el sistema judicial y habían sido nombrados vocales por el propio mariscal Castilla durante su anterior gobierno, mientras que el tercero había sido nombrado por el Libertador un mes después que el departamento lo reconociera como el legítimo gobernante del país. Solo era necesario nombrar un cuarto juez para llenar una vocalía que en ese instante se encontraba vacante. ${ }^{56}$

El prefecto tampoco informaba de exoneraciones entre los jueces de primera instancia del departamento, pero su informe no solo era de carácter político sino que además entregaba detallada información sobre la labor profesional de los jueces y el contexto en que la realizaban. Así por ejemplo, daba cuenta del buen desempeño de los dos jueces de Puno y del juez de Carabaya, al mismo tiempo que hacía notar problemas en el desempeño de los jueces de Lampa y Huancané, a pesar de que estos habían sido nombrados por el propio Libertador en mayo de 1854.

En el caso Lampa, el prefecto destacaba que la mayoría de los juicios afectaban a «los vecinos españoles de la provincia», y entre ellos «uno de los más notables por su posición social, por su fortuna, por la naturaleza de sus negocios y por sus vastas relaciones mercantiles» era «don Rudecindo Barrionuevo», padre del juez local José María Barrionuevo, relación que hacía «imposible la buena administración de justicia». Algo semejante ocurría, según el prefecto, con Clemente Manríquez, juez de Huancané nombrado en 1848 durante el primer gobierno de Ramón Castilla. Sin existir muchos pleitos en la provincia, el juez Manríquez destinaba su tiempo preferentemente a sus «especulaciones mercantiles» y a estrechar «relaciones con la porción del vecindario de más intereses», a lo que se sumaba «sus

55 Bando en que los habitantes de Puno invisten al gran mariscal Ramón Castilla con el supremo poder ejecutivo de la República, 15 de abril de 1854. En El Comercio 4416, 24 de abril de $1854,2-3$.

56 Cuadro informativo y detallado de los empleados del poder judicial en el departamento de Puno. Puno, 30 de enero de 1855. AGN, Ministerio de Justicia, Ramos del Ministerio de Justicia, Prefectura de Puno, RJ 1.5.13, documento no numerado, 1-5. 
contratos y negociaciones con los indígenas de la provincia, lo que le impedía administrar justicia con imparcialidad». ${ }^{57}$ Por estas razones, el prefecto recomendaba al gobierno trasladar al juez Manríquez desde Huancané a la provincia de Azángaro, donde la mayor cantidad «de vecindario respetable le estimularía a desempeñarse [en] sus deberes con más contracción», mientras proponía que el juez de Lampa, José María Barrionuevo, fuera trasladado a la judicatura de Huancané y finalmente redestinar a José Manuel Calle, hasta ese momento juez de Azángaro, a la judicatura de Lampa. ${ }^{58}$

Aunque en Puno el informe del prefecto no era de carácter político por la ya mencionada lealtad de dicho territorio a Ramón Castilla, de todas formas el representante local del poder ejecutivo pedía al gobierno central que se decretaran las traslaciones de jueces como se indicaba, argumentando que la petición se animaba exclusivamente en el deseo de conseguir la «más segura reorganización del poder judicial». ${ }^{59} \mathrm{Sin}$ mediar informes de la Corte Superior de Puno o de la Corte Suprema de Justicia, entes encargados según la constitución de fiscalizar el funcionamiento de la justicia de primera instancia, en el decreto del 31 de marzo de 1855, que nombraba a todos los empleados judiciales del territorio, el gobierno del mariscal Castilla siguió cada una de las recomendaciones del prefecto de Puno, ${ }^{60}$ al igual que había hecho con los informes provenientes de La Libertad.

Mientras el ejecutivo decretaba los nombramientos de todos los jueces de la República sin consultar a las cortes superiores, la discusión sobre la reforma de la judicatura se trasladó a la prensa, concentrándose casi exclusivamente en la labor de la Convención Nacional y el proyecto de nueva constitución que buscaba no solo establecer la amovilidad de los jueces, sino también limitar el periodo de tiempo en que estos podían cumplir sus funciones.

Quienes apoyaban la amovilidad argumentaban que el carácter vitalicio de la judicatura era un «contrasentido» con los principios «de la democracia moderna», donde ningún cargo público debía ser perpetuo. ${ }^{61}$ Otro artículo publicado en septiembre de 1855 insistía en que la inamovilidad era una «anomalía, una monstruosidad o un contrasentido» que atacaba «la esencia misma» de la república, por lo que llamaba a terminar con la

57 Ibidem, 3-3v.

58 Ibidem, $3 \mathrm{v}$.

59 Idem.

60 Decreto nombrando el personal de todos los tribunales y juzgados de la República, Chorrillos, 31 de marzo de 1855. En Oviedo, 1864, XII, 60.

61 El Comercio 4837, 15 de septiembre de 1855, 3. 
perpetuidad por ser un privilegio odioso «a la igualdad de derechos» y contrario «a la dignidad del ciudadano y a la forma de gobierno». ${ }^{62}$

El artículo también entendía la rotación de los jueces como un arma efectiva en la lucha contra la corrupción de la judicatura ya que la inamovilidad «mata el estímulo» debido a que quien «ha conseguido un destino se cuida poco de estudiar y de hacer brillar su justificación, habiendo asegurado su entrada de por vida». Sin incentivos para mejorar su labor y «escudado en la inamovilidad», el juez sabía que la «indolencia o falta de rectitud» no traía consecuencias, por lo que el artículo concluía que la perpetuidad en los cargos se trasformaba en la garantía «para ejercer permanentemente la abominable inmoralidad con sus abusos, infracciones e injusticias». La rotación en los cargos, por el contrario, traería múltiples beneficios, estimulando la competencia entre la juventud, la que «rivalizará para adornarse de un mérito indisputable que lo señale directamente como acreedor al puesto que alterna». ${ }^{63}$

Para quienes se oponían a la medida, los políticos que promovían la amovilidad actuaban por «ignorancia o por error», ya que desconocían el hecho de que la inamovilidad de la judicatura era el «fruto de la experiencia y de la civilización en las naciones más antiguas de la tierra, cuyo saludable principio han acogido todas las demás con cortas excepciones». El artículo citaba el ejemplo de Estados Unidos, «el pueblo más libre de la tierra», donde «no hay temor a la perpetuidad de los jueces por extensas y trascendentales que sean sus atribuciones, y a nadie se le ocurre alterarlas ni mucho menos hacer alternativo y electivo el poder judicial». ${ }^{64}$

Junto a lo anterior, el asunto de fondo para los opositores era resguardar la independencia de la judicatura y garantizar su despolitización. Según el artículo publicado en El Comercio el 29 de septiembre, independientemente de todos los problemas que enfrentaba el poder judicial, existía la necesidad urgente de «sacar a la magistratura de todas sus clases de la esfera política en que se está agitando [y] en que se está desacreditando», por lo que la inamovilidad judicial no podía supeditarse a la mayor o menor inestabilidad política del país. Por el contrario, argumentaba que la inamovilidad era el único medio «para sacar de algún modo a la justicia de la esfera política que la sofoca y la mata; no hay otro medio para elevarla a la altura de su nombre, separándola del terreno para ella cenagoso de los

62 El Comercio 4849, 29 de septiembre de 1855, 3.

63 Idem.

64 El Comercio 4851, 2 de octubre de 1855, 7. 
partidos». El artículo reconocía que, a pesar de la inamovilidad, en el país se hacían sentir «tristes y dolorosas influencias» sobre la judicatura, pero que sin embargo aquello, la inamovilidad era «lo que más se acerca a una garantía apetecible». ${ }^{65}$

En su afán por contener la corrupción, el autor del artículo argumentaba que el gobierno malentendía el liberalismo promoviendo reformas contrarias a su espíritu, dejándose llevar por las constantes críticas que los litigantes publicaban en la prensa contra los jueces. Resaltaba, por lo tanto, que era «indudable que la inamovilidad judicial ha sido y es una máxima del liberalismo» y que desde «hace muchos años que se la proclama sin contradicción como uno de los medios capitales para asegurar la rectitud de la justicia». Por eso el artículo finalizaba enfatizando que los sistemas constitucionales, como el que Perú debatía en esos momentos, la invocaban y establecían «sin que ningún publicista, ningún hombre de Estado, ninguna persona importante en el moderno orden social levanta[ra] su voz para combatirla». ${ }^{66}$

Pocos días después, un nuevo artículo publicado en las páginas de $E l$ Comercio insistía en que la administración de justicia no podía estar regida por los cambiantes intereses políticos. La justicia no era un «negocio del liberalismo», como tampoco debía ser «jamás negocio del ministerialismo o de oposición, progresivo o conservador». Los principios de la justicia no debían supeditarse a «las efímeras disposiciones de los partidos, sino a las reglas eternas del derecho y la razón», alejándola de las «exageraciones y mezquindades» y protegiéndola de «los embates de los intereses momentáneos», para que se desarrolle «en una esfera más sublime, exenta del influjo de las pasiones, del capricho y de la fuerza». ${ }^{67}$

Para los opositores, el proyecto de amovilidad traería también problemas prácticos que profundizarían los que ya afectaban el desarrollo de la carrera judicial. Limitando la labor de los jueces a dos o cuatro años, un artículo advertía que la judicatura se convertiría en «un vasto campo de mercenarios», desincentivando a los abogados de seguir el camino de la judicatura. La falta de estabilidad, sumada a otros problemas que ya afectaban al sistema, como el irregular pago de salarios y las persecuciones que sufrían de parte de los litigantes, haría que los abogados prefirieran seguir la

65 El Comercio 4849, 29 de septiembre de 1855, 3.

66 Ibidem, 4.

67 El Comercio 4853, 4 de octubre de 1855, 4. 
práctica privada de su profesión para «asegurar, de un modo independiente, la subsistencia de su familia». ${ }^{6}$

El tema de la estabilidad no era un problema menor, a lo que se sumaba que en Perú no existían suficientes abogados como para implementar la rotación de los cargos judiciales como se establecía en el proyecto de nueva constitución. En Perú, al igual que en otros países de América y Europa, la caída del antiguo régimen desvinculó la labor de los jueces y abogados del ámbito monárquico, modernizando el ejercicio de la abogacía durante el siglo XIX. El número de abogados aumentó significativamente en pocas décadas, se diversificó socialmente y se transformó en parte importante de la burocracia estatal republicana. ${ }^{69}$ En el caso peruano, el número de abogados casi se cuadruplicó en menos de cincuenta años, pasando de 177 en $1813,{ }^{70}$ a 657 en $1861,{ }^{71}$ pero a pesar del aumento el número era totalmente insuficiente para cubrir las necesidades creadas por una creciente burocracia republicana que promovía la profesionalización de la judicatura, más aún si la constitución buscaba limitar la cantidad de años que podían ejercer los jueces.

De los 657 abogados existentes en el Perú en 1861, solo 286 ejercían la profesión de forma privada, mientras que 263 se desempeñaban en el sistema judicial, ya fuese como jueces de primera instancia, vocales de las cortes superiores, relatores, fiscales o secretarios. ${ }^{72} \mathrm{~A}$ esto se agregaba la concentración de profesionales en ciudades como Lima, Arequipa y Cusco y su reticencia ya sea a ejercer la profesión o a aceptar destinos como jueces en zonas periféricas. Como vimos anteriormente, los traslados a localidades del interior del país eran vistos por algunos jueces como un castigo o retroceso en su carrera judicial, lo que según el ministro de Justicia generaba «graves inconvenientes para la provisión de judicaturas de primera

68 El Comercio 4847, 27 de septiembre de 1855, 6.

69 En Barcelona el número de abogados pasó de 215 en 1802 a 653 en 1887. En Nueva Granada, a fines de la época colonial el número de abogados era de aproximadamente 150, subiendo a 556 en 1849 para el territorio colombiano. En el caso de Chile los abogados pasaron de 77 en 1797 a 282 en 1854, y en el Río de la Plata existían 98 en 1802, número que subió a 439 en la Argentina de 1869. Las cifras provienen de: Jacobson, 2009, 31; Uribe-Urán, 2000, 239; Uribe-Urán, 2008, 311; Pérez Perdomo, 2006, 33 y 89.

70 Uribe-Urán, 2000, 240.

71 Matrícula de los abogados de la República. En El Peruano, año 20, tomo 41, 31 de julio de $1861,1-8$.

72 Idem. La diferencia entre el total y la suma de quienes ejercen la abogacía o son parte del sistema judicial está explicada por aquellos que, teniendo permiso para ejercer, no lo hacen por dedicarse a otras actividades, como por ejemplo sacerdotes. 
instancia por la repugnancia que siempre oponen los letrados de alguna reputación a servir fuera de las capitales de los departamentos». ${ }^{73}$

Los debates en la Convención Nacional en gran parte repitieron los argumentos a favor y en contra de la amovilidad publicados en la prensa de Lima, generando posturas irreconciliables que resumió de buena forma el diputado por Cusco Pio Benigno Mesa, al decir que «se ha querido entender por amovilidad la arbitraria destitución de los jueces, y por inamovilidad, la falta de responsabilidad, y el perpetuo despotismo del poder judicial». ${ }^{74}$ Una tercera posición surgió en la Convención, sin embargo, proponiendo que la constitución estableciera que «los magistrados y jueces gozarán de sus destinos mientras la moralidad de su conducta esté en armonía con su elevada misión». ${ }^{75}$

La propuesta era ambigua para el diputado por Lima Felipe Cortés, ya que esta no zanjaba de manera clara y directa el asunto de si los jueces serían o no amovibles, al no establecer un periodo de tiempo en que estos debían cumplir sus funciones, independientemente de que delinquieran o no. Para el diputado Mesa, partidario de la amovilidad, a esto se sumaba que la propuesta establecía que la remoción de un magistrado podía verificarse «por solo pedirlo el Senado, el Ejecutivo, o por el voto de censura de la Cámara de Diputados, o por la simple queja de los particulares, sin haberse sometido precisamente a juicio», lo que afectaría a la independencia de los jueces al quedar estos «a merced de los poderes públicos». ${ }^{76}$

La propuesta de un punto intermedio entre la amovilidad y la perpetuidad de los cargos judiciales no prosperó y la constitución finalmente estableció en su artículo 125 que tanto los jueces de primera instancia, como los vocales de las cortes superiores y Suprema, durarían un tiempo determinado en sus cargos, plazo que sería definido en el futuro a través de una ley. El artículo 127 por su parte, establecía que los vocales de la Corte Suprema serían nombrados por el Congreso de una terna propuesta por el ejecutivo, mientras los vocales de las cortes superiores y jueces de primera instancia serían elegidos por el ejecutivo a partir de nombres propuestos por las juntas departamentales. ${ }^{77}$

73 Memoria anual del ministro de Justicia para el año 1848. En El Comercio 3041, 23 de agosto de 1849 .

74 Convención Nacional, sesión del 15 de octubre de 1855. En El Comercio 4864, 17 de octubre de 1855, 2-3.

75 Ibidem, 3.

76 Idem.

77 Oviedo, 1861, I, 163. 


\section{Conclusiones}

Más allá de que se estuviera a favor o en contra de la reforma, era un hecho concreto que el nuevo texto constitucional significaba un quiebre radical con lo que estipulaba la Constitución de 1839 en materia judicial. El poder de trasladar a los jueces a voluntad del ejecutivo se mantenía, pero a esto se agregaba que las cortes superiores del país perdían toda injerencia en la designación de los jueces de primera instancia, al mismo tiempo que se coartaba la existencia de una carrera judicial al limitar el tiempo en que los jueces podían ejercer como tales.

Esa radicalidad hizo que el apoyo al nuevo texto constitucional entre algunos sectores, que creían en la necesidad de un cambio pero no necesariamente se identificaban con las propuestas del gobierno, fuera débil. Un editorial de El Comercio pocos días después de promulgada la constitución retrataba claramente ese sentimiento, dando a entender que, ante los problemas de la judicatura, cualquier cambio podría ser positivo aunque no se tuviera mayor convencimiento de ello. Según los editores, el periódico había sido un decidido adversario de la amovilidad, por considerarla una «medida imprudente, que produciría los más funestos resultados». Sin embargo, estando convencidos que de seguir todo igual en materia judicial «no existe la menor esperanza de mejora», la amovilidad «nunca haría peor la situación» y por eso ahora la apoyaban. ${ }^{78}$

La tibieza del apoyo de El Comercio a la reforma de la judicatura no era excepcional. El propio gobierno se había distanciado de la base liberal que lo había apoyado en un inicio y el mismo presidente Castilla puso en duda la jura de la nueva constitución, dejando en evidencia las profundas fracturas internas entre quienes habían iniciado la revolución contra Echeñique. Aunque la constitución fue finalmente aprobada por el ejecutivo, su débil base de apoyo no tardó en generar divisiones aún más profundas que finalmente desembocaron en el levantamiento armado de sectores conservadores, llevando al país a una nueva guerra civil y, de paso, haciendo que la nueva constitución fuera inviable. ${ }^{79}$

Aunque una nueva constitución de carácter más moderado fue promulgada en 1860, varios elementos de cambio incorporados en la de 1856 se mantuvieron, entre ellos la abolición de la esclavitud y el fin de los fueros, cosa que no ocurrió con las reformas a la judicatura. Estas desaparecieron

78 El Comercio 5166, 19 de octubre de 1856, 1.

79 Sobrevilla, 2004, 238-243. 
de la Constitución de 1860, además de mantenerse vigente el reglamento de tribunales de 1854 .

Como plantea Julio Pinto en un reciente artículo, no existe entre los historiadores un consenso a la hora de explicar las motivaciones que ayudaron a sustentar las propuestas de cambios del gobierno castillista, siendo entendidas ya sea como reformas instrumentales y oportunistas frente a la contingencia política de la época, como consecuencia del «doctrinarismo liberal» o, como sostiene el propio Pinto, como una «genuina convicción sobre la necesidad de dialogar con los sectores populares para una construcción política más legítima y duradera». ${ }^{80}$

¿Cómo entender las fracasadas reformas al sistema judicial dentro de estos debates sobre la construcción del Estado peruano? Como vimos en las páginas iniciales de este artículo, la reforma a la judicatura era vista por el entorno liberal que inicialmente apoyaba al presidente Castilla como una medida urgente y que el propio ministro de Justicia, Pedro Gálvez, definió ante la Convención Nacional como «tan enérgicas como necesarias» en la presentación de su memoria anual de $1855 .{ }^{81}$

Las críticas a la amovilidad judicial aparecidas en la prensa, por el contrario, la mostraban como una reforma que tenía el potencial de fortalecer e institucionalizar el autoritarismo que había caracterizado al caudillismo peruano al otorgarle rango constitucional al intervencionismo del ejecutivo sobre la judicatura que se había dado en la práctica desde los inicios de la República. A esto se sumaba el intento por limitar el tiempo en que los jueces podían asumir dichas funciones, medidas que estaban lejos por lo tanto de un liberalismo que debía garantizar la independencia de la judicatura frente a los otros poderes del Estado.

Liberales o no, llama la atención que estas medidas eran un ataque a los abogados como gremio. Muchos de ellos, como el propio ministro Pedro Gálvez, eran parte del creciente número de letrados que iban ganando terreno en la hasta entonces militarizada vida política peruana. En este contexto, la amovilidad judicial y el límite temporal para ejercer funciones judiciales decretado por la Constitución de 1856 no pudo haber sido una medida que buscara otorgar mayores fuentes laborales al creciente número de juristas en el país. Como vimos páginas atrás, el número de profesionales era aún insuficiente para cubrir las plazas que el sistema demandaba, más aún si se proponía la rotación en los cargos.

80 Pinto, 2016, 556.

81 Memoria que presenta a la Convención Nacional, 1855, 4. 
En síntesis, la reforma parece haber sido más un esfuerzo por limitar la independencia de la judicatura, concordante con las prácticas caudillistas que caracterizaron las primeras décadas de vida republicana, y no una reforma inspirada por el liberalismo, lo que hace más significativo el hecho de que no logró consenso para subsistir. La nueva Constitución de 1860 reestableció la inamovilidad de los jueces y vocales, junto con devolver al poder judicial la prerrogativa de proponer ternas al ejecutivo para el nombramiento de jueces de primera instancia y vocales de las cortes superiores. ${ }^{82}$ Así se puso fin a una reforma que, aunque radical, parecía coherente con las prácticas centralizadoras que se experimentaban a diario en el país desde hacía décadas.

Recibido el 13 de diciembre de 2017 Segunda versión el 18 de julio de 2018 Aceptado el 13 de septiembre de 2018

\section{Referencias bibliográficas}

Aguirre, Carlos, «Tinterillos, Indians, and the State: Towards a History of Legal Intermediaries in Post-Independence Peru», en Kirmse, S. B. (ed.), One Law for All? Western models and Local Practices in (Post-)Imperial Contexts, Frankfurt, Campus Verlag, 2012, 119-151.

Annino, Antonio, «Soberanías en lucha», en Annino, A. y Guerra, F. X. (coords.), Inventando la nación. Iberoamérica, siglo XIX, México, Fondo de Cultura Económica, 2003, 152-184.

Barriera, Darío, «¿Qué nos enseña la historia de las instituciones judiciales?», en Bandieri, S. y Fernández, S. (coords.), La historia argentina en perspectiva local y regional. Nuevas miradas para viejos problemas, Buenos Aires, Teseo, 2017, tomo II, 133-156.

Basadre, Jorge, Historia de la República del Perú, Lima, Ediciones Historia, 1961, tomo III.

Bilot, Pauline y Whipple, Pablo, «Los desafíos de la justicia republicana. Profesionalización e independencia de la judicatura en Chile y Perú durante el siglo XIX», en Francesco, A. de; Mascilli Migliorini, L. y Nocera, R. (coords.), Entre Mediterráneo y Atlántico. Circulaciones, conexiones y miradas, 17561867, Santiago, Fondo de Cultura Económica, 2014, 477-500.

Candioti, Magdalena, «Los jueces de la revolución: pertenencia social, trayectorias políticas y conocimiento experto. Buenos Aires, 1810-1830», en Alabart, M.; Fernández, M.A. y Pérez, M.A. (comps.), Buenos Aires, una sociedad que se

82 Constitución política del Perú, 1860, 25. 
transforma. Entre la colonia y la Revolución de Mayo, Buenos Aires, Prometeo, 2010, 287-324.

Colección de los recursos de los antiguos magistrados despojados por la renovación judicial, Lima, Imprenta de José M. Masías, 1832.

Constitución política del Perú, reformada por el Congreso de 1860, Lima, Imprenta de José M. Masías, 1860.

Corva, María Angélica, "IÍntegros y competentes”. Los magistrados de la provincia de Buenos Aires en la segunda mitad del siglo XIX», en Barriera, D. (comp.), Justicias y fronteras. Estudios sobre historia de la justicia en el Río de la Plata. Siglos XVI-XIX, Murcia, Editum, 2009, 179-204.

Dargent, Eduardo, «Determinants of Judicial Independence: Lessons from Three "Cases" of Constitutional Courts in Peru (1982-2007)», Journal of Latin American Studies, 41:2, Cambridge, 2009, 251-278.

Del Águila Peralta, Alicia, La ciudadanía corporativa. Política, constituciones y sufragio en el Perú (1821-1896), Lima, Instituto de Estudios Peruanos, 2013.

De la Puente Brunke, José, «"Siempre los jueces tienen malquerientes”: Reflexiones sobre el juez y su relevancia social en la historia del Perú», Revista Histórica, Academia Nacional de la Historia, XLV, Lima, 2011-2012, 433-455.

Fuentes, Manuel A., Aletazos del Murciélago. Colección de artículos publicados en varios periódicos por Manuel A. Fuentes, Paris, Imprenta de Ad. Lainé y J. Havard, 1866.

Galante, Mirian, «Conflictos de jurisdicción, reorganización del territorio y delimitación de los poderes. Tlaxcala, 1821-1833», en Galante, M.; Irurozqui, M. y Argeri, M. E., La razón de la fuerza y el fomento del derecho. Conflictos jurisdiccionales, ciudadanía y mediación estatal (Tlaxcala, Bolivia, Norpatagonia, siglo XIX), Madrid, CSIC, 2011, 29-87.

Gootemberg, Paul, Imagining Development. Economic Ideas in Peru's «Fictitious Prosperity» of Guano, 1840-1880, Berkeley, University of California Press, 1993.

Jacobson, Stephen, Catalonian's Advocates. Lawyers, Society and Politics in Barcelona, 1759-1900, Chapel Hill, University of North Carolina Press, 2009.

Krupa, Christopher y Nugent, David, «Off-Centered States: Rethinking State Theory an Andean Lens», en Krupa, C. y Nugent, D. (eds.), State Theory and Andean Politics. New Approaches to the Study of Rule, Philadelphia, University of Pennsylvania Press, 2015, 1-31.

Landa, César, The Scales of Justice in Peru: Judicial Reform and Fundamental Rights, London, University of London, Institute of Latin American Studies, 2001.

McEvoy, Carmen, La utopía republicana: ideales y realidades en la formación de la cultura política peruana (1871-1919), Lima, Pontificia Universidad Católica del Perú, 1997. 
Memoria que presenta a la Convención Nacional de 1855 el Ministro encargado del despacho de Justicia, Culto y Beneficencia, Lima, Tipografía de la Dirección General de Estudios, 1855.

Oviedo, Juan, Colección de leyes, decretos y órdenes publicadas en el Perú desde el año de 1821 hasta el 31 de diciembre de 1859, Lima, Felipe Bailly Editor, tomos I, XI y XII, 1861, 1863 y 1864.

Pásara, Luis, Tres claves de la justicia en el Perú, Lima, Pontificia Universidad Católica del Perú, 2010.

Peralta, Víctor, «La guerra civil peruana de 1854. Los entresijos de una revolución», Anuario de Estudios Americanos, 70, 1, Sevilla, 2013, 195-219.

Pérez-Perdomo, Rogelio, Latin American Lawyers. A Historical Introduction, Stanford, Stanford University Press, 2006.

Pinto, Julio, «La construcción social del Estado en el Perú: El régimen de Castilla y el mundo popular, 1845-1856», Historia, 49-II, Santiago de Chile, 2016, 547-578.

Quirós, Mariano Santos de, Colección de leyes, decretos y órdenes publicados en el Perú desde su independencia en el año de 1821, hasta 31 de diciembre de 1834, Lima, Imprenta de José Masías, 1837, tomo 4.

Quiroz, Alfonso W., La deuda defraudada. Consolidación de 1850 y dominio económico en el Perú, Lima, Instituto Nacional de Cultura, 1987.

Quiroz, Alfonso W., Corrupt Circles: A History of Unbound Graft in Peru, Washington D.C., Woodrow Wilson Center Press, 2008.

Ragas, José, «La distorsión de la voluntad. Corrupción y sufragio en el Perú (18491851)», en Irurozqui, M. (ed.), La mirada esquiva: reflexiones sobre la interacción del Estado y la ciudadanía en los Andes, Madrid, CSIC, 2005, 215-232.

Ramos, Carlos, La pluma y la ley. Abogados y jueces en la narrativa peruana, Lima, Fondo Editorial de la Universidad de Lima, 2007.

Sobrevilla, Natalia, «El proyecto liberal y la Convención de 1855», en McEvoy, C. (ed.), La experiencia burguesa en el Perú (1840-1940), Madrid, Iberoamericana, 2004, 223-243.

Soifer, Hillel David, State Building in Latin America, New York, Cambridge University Press, 2015.

Uribe-Urán, Víctor M., «La América Latina colonial y postcolonial: ¿tierra de abogados y leguleyos?», en Uribe-Urán, V. M. y Ortiz Mesa, L. J. (eds.), Naciones, gentes y territorio. Ensayos de historia e historiografía comparada de América Latina y el Caribe, Medellín, Universidad de Antioquia, 2000, 229-269.

Uribe-Urán, Víctor M., Vidas Honorables. Abogados, familia y política en Colombia 1780-1850, Medellín, Editorial EAFIT/Banco de la República, 2008.

Whipple, Pablo, La gente decente de Lima y su resistencia al orden republicano: Jerarquías sociales, prensa y sistema judicial durante el siglo XIX, Lima/Santiago, Instituto de Estudios Peruanos/DIBAM, 2013a. 


\section{PABLO WHIPPLE MORÁN}

Whipple, Pablo, «Carencias materiales, respetabilidad y prácticas judiciales en Perú durante los inicios de la República», Historia Crítica, 49, Bogotá, 2013b, 55-79.

Whipple, Pablo, «La "milicia togada" contra la "milicia armada". Disputas por el poder entre jueces, prefectos e intendentes en Perú durante los inicios de la República», en Palma Alvarado, D. (ed.), Delincuentes, policías y justicias. América Latina, siglos XIX y XX, Santiago de Chile, Ediciones Universidad Alberto Hurtado, 2015, 391-410.

Whipple, Pablo, «Guerra a los abogados. La defensa libre y los debates sobre el monopolio de los abogados y la corrupción de la justicia peruana, 18411862», en Rosenmüller, C. y Ruderer, S. (eds.), «Dádivas, dones y dineros». Aportes a una nueva historia de la corrupción en América Latina desde el imperio español a la modernidad, Madrid/Frankfurt, Iberoamericana Vervuert, 2016, 127-146. 